\title{
CISTO DE ÚRACO EM ADULTOS SIMULANDO ABDÔMEN AGUDO
}

\author{
ADULTS URACHAL CYST SIMULATING ACUTE ABDOMEN
}

\section{Emanuel da Silva Vieira Júnior ${ }^{1}$; Rone Antônio Alves de Abreu, TCBC-SP²; Manlio Basilio Speranzini, ECBC-SP ${ }^{3}$}

\section{INTRODUÇÃO}

O úraco é uma estrutura fetal, remanescente do alantóide, que se estende da cúpula da bexiga ao umbigo e que após o nascimento se oblitera ${ }^{1,2}$. Caso persista, ocasiona várias anomalias, algumas das quais podem se manifestar como abdômen agudo cirúrgico. A sua baixa frequiência e manifestações clínicas, na maioria das vezes pouco específicas, fazem com que sejam confundidas com outras afecções mais comuns, o que muitas vezes retarda seu diagnóstico.

Tivemos a oportunidade de diagnosticar e tratar três destas anomalias em adultos e que simulavam abdômen agudo.

\section{RELATO DO CASO}

De 1996 a 2003 foram diagnosticados e tratados três pacientes adultos com cisto de úraco infectado no Conjunto Hospitalar do Mandaqui, sendo dois do sexo masculino e um do feminino, com idades variando de 19 a 38 anos. Todos apresentavam dor localizada no hipogástrico, havendo sinais flogísticos locais e febre $\left(38\right.$ e $\left.39^{\circ} \mathrm{C}\right)$ em dois dos três pacientes. Todos apresentavam algum grau de leucocitose com neutrofilia. Um paciente (caso $\mathrm{n}^{\circ} 2$ ) apresentava drenagem purulenta espontânea pela cicatriz umbilical. Outra paciente (caso ${ }^{\circ} 3$ ) foi submetida à drenagem de abscesso da parede abdominal. A fistulografia realizada posteriormente contrastou uma cavidade e alça do intestino delgado.

O ultra-som (USG) de abdome demonstrou em todos a presença de tumor cístico, de paredes espessadas, com conteúdo líquido hiperecogênico e na paciente do caso $n^{\circ} 3$ a presença de bolhas de ar. Em um paciente (caso $n^{\circ} 1$ ) a tomografia mostrou formação perivesical, junto à bexiga (Figura 1).

O tratamento consistiu na exérese do cisto e do trajeto fistuloso; na paciente do caso $\mathrm{n}^{\mathbf{0}} 3$, foi necessária também a ressecção de $10 \mathrm{~cm}$ de íleo aderido e fistulizado, com reconstrução íleo-ileal (Figura 2).
Todos tiveram boa evolução com alta hospitalar entre $2^{\circ}$ e $7^{\circ}$ dia pós-operatório. Foram revistos no ambulatório, sem queixas e com boa cicatrização.

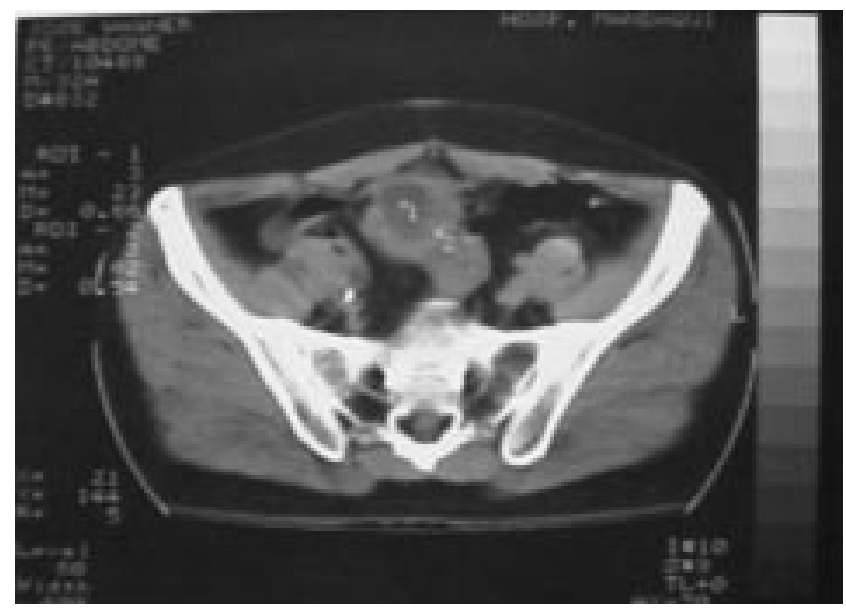

Figura 1 - Tomografia computadorizada (caso de no 1), evidenciando massa perivesical.

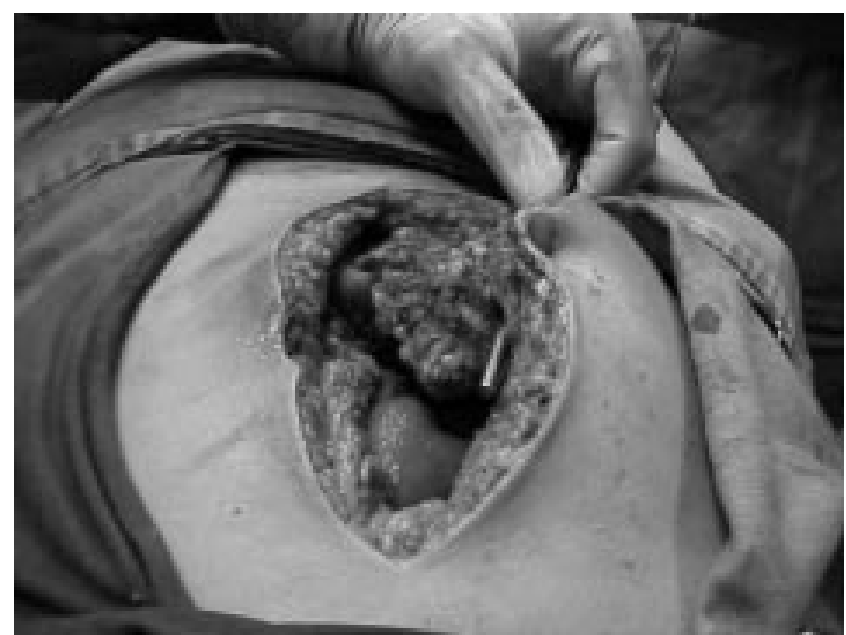

Figura 2 - Ato cirúrgico (Caso de $n^{o} 3$ ). Trajeto fistuloso infraumbilical, penetrando na cavidade (aberta) do cisto. A alça ileal aderida e fistulizada encontra-se logo abaixo.

1. Médico Residente do Conjunto Hospitalar do Mandaqui - Secretaria de Estado da Saúde, São Paulo-SP - Serviço de Cirurgia Geral

2. Coordenador da Residência Médica de Cirurgia Geral do Conjunto Hospitalar do Mandaqui; Mestre e Doutor em Cirurgia pela Escola Paulista de Medicina - UNIFESP.

3. Professor Titular de Cirurgia do Aparelho Digestivo da Faculdade de Medicina do ABC - SP; Chefe do Serviço de Cirurgia Geral do Conjunto Hospitalar do Mandaqui. 


\section{DISCUSSÃo}

Nos pacientes aqui relatados as anomalias do úraco se apresentaram como cisto e fístula umbilical e suas manifestações clínicas simulavam abdômen agudo cirúrgico.

$\mathrm{O}$ cisto de úraco corresponde a $30 \%$ das anomalias uracais, estando presente como massa palpável ou abscesso, na linha mediana desde o hipogástrio até a região peri-umbilical; um terço dos casos é diagnosticado em adultos ${ }^{2}$.

$\mathrm{Na}$ maioria das vezes, é assintomático sendo, em geral, diagnosticado na vigência de complicações infecciosas provocadas por contaminação hematogênica, linfática ou vesical caso persista a comunicação com a bexiga urinária ${ }^{3}$. A eliminação de secreções pela cicatriz umbilical, como no paciente do caso 2 , caracteriza a fístula umbilical ${ }^{1,2}$. Mais raramente, se manifesta por dor como no paciente do caso de $n^{\circ} 1$.

A ruptura espontânea para peritônio livre $^{1}$ ou bloqueada por alças intestinais é rara. É provável que ocorram, inicialmente, aderências de alças intestinais com o úraco abscedado e posteriormente a fistulização para a pele ${ }^{4}$, espontânea ou cirúrgica, ou para o íleo como na paciente do caso de $\mathrm{n}^{\mathrm{o}} 3$.

Os quatro casos de fístulas intestinais, descritos na literatura, comprometiam o sigmóide ${ }^{4}$, não havendo referências destas para o intestino delgado. $\mathrm{Na}$ paciente do caso de $\mathrm{n}^{\circ}$ 3, apesar de identificadas bolhas de ar no abscesso pela USG, o diagnóstico somente foi feito após fistulografia e confirmado na exploração cirúrgica (Figura 2).

A presença de sinais flogísticos na região peri-umbilical e/ou no hipogástrio deve alertar o médico quanto ao diagnóstico de cisto de úraco infectado e a sua confirmação será feita por exames de imagem, destacando-se a importância do ultra-som que tem acerto diagnóstico de $90 \%{ }^{1,3}$.

$\mathrm{O}$ tratamento, em geral, se restringe à exérese do cisto; quando houver fistulização para tecidos ou vísceras vizinhas ${ }^{5}$ será necessária a ressecção da parte do segmento envolvido.

\begin{abstract}
Urachus anomalies are generally asymptomatic, but when infected can simulate acute abdomen. This anomaly has to be deemed when abdominal tenderness is associated with inflammation signs in parumbilical or hypogastric regions. Ultrasonography has great sensibility to settle down the diagnosis as observed from our three cases. Ultrasonography images with air suggest intestinal fistula in most cases with sigmoid or ileum as shown here (Rev. Col. Bras. Cir. 2007; 34(1): 67-68).
\end{abstract}

Key words: Urachal cyst; Abdomen, acute; Complications; Ultrasonography .

\section{REFERÊNCIAS}

1. Yu JS, Kim KW, Lee HJ, Lee YJ, Yoon CS, Kim MJ. Urachal remnant diseases: spectrum of CT and US findings. Radiographics. 2001;21(2):451-61.

2. McCollum MO, Macneily AE, Blair GK. Surgical implications of urachal remnants: presentation and management. J Pediatr Surg. 2003;38(5):798-803.

3. McCrystal DJ, Ewing MJ, Lambrianides AL. Acquired urachal pathology: presentation of five cases and a review of the literature. ANZ J Surg. 2001;71(12):774-6.

4. Gomez-Barbadillo J, Plata Rosales J, Espinoza Guzman E, Castilla Cabezas J, Dias Lopez C, Soria Alvarez C, Ramos Cejudo F, Gutierrez Sainz J. Urachal-sigmoid fistula in an adult male without urachal cyst. Rev Esp Enferm Dig. 2002;94(7):430-4.
5. Molderez CM, Wouters KB, Bergmans GB, Michiels GK. Umbilical discharge: review of 22 cases. Acta Chir Belg. 1995;95(3):166-9.

Como citar este artigo:

Vieira Júnior ES, Abreu RAA, Speranzini MB. Cisto de úraco em adultos simulando abdômen agudo. Rev Col Bras Cir. [periódico na Internet] 2006 Nov-Dez;33(6). Disponível em URL: www.scielo.br/ $\mathrm{rcbc}$

Endereço para correspondência:

Manlio Basílio Speranzini

Av Brig Faria Lima 2553

01452-000 - São Paulo - SP 